\title{
Accuracy of preliminary remission criteria some JIA category F Fantini $^{2}$, A Salmaso ${ }^{2}$, V Gerloni ${ }^{2}$, M Gattinara ${ }^{2}$, B Teruzzi ${ }^{2}$, I Pontikaki ${ }^{2}$ and A Lurati*1
}

Address: ${ }^{1}$ Fornaroli Hospital Rheumatology Unit, Magenta, Italy and ${ }^{2}$ Gaetano PIni Institute Chair of Rheumatology, Milan, Italy

* Corresponding author

from $15^{\text {th }}$ Paediatric Rheumatology European Society (PreS) Congress

London, UK. 14-17 September 2008

Published: 15 September 2008

Pediatric Rheumatology 2008, 6(Suppl I):PI05 doi:I0.II86/I546-0096-6-SI-PI05

This abstract is available from: http://www.ped-rheum.com/content/6/SI/PI05

(C) 2008 Fantini et al; licensee BioMed Central Ltd.

To evaluate disease course in juvenile idiopathic arthritis (JIA) by applying newly developed preliminary definitions of remission, to assess probability of relapse of disease. Charts of patients with JIA followed since 1970 were reviewed. First episode of remission off medication status, as defined by Wallace et al., has been focused. The cohort included 761 patients (67.8\% females, 32.2\% males) with JIA. Mean disease onset age $( \pm S D)$ was $6.25 \pm 4.4$ years (range 0.5-15.9). Disease mean duration to last visit was $10.02 \pm 4.31$ years. Follow up mean period was $7.6 \pm 6.4$ years (range 1.5-35 years). A total of 263 (34.56\%) patients achieved remission according to criteria (persistent oligoarthritis $42.9 \%$, extended oligoarthritis $13.1 \%$, seronegative polyarthritis $22.4 \%$, systemic arthritis $33.7 \%$, enthesitis related arthritis (ERA) plus juvenile psoriatic arthritis (JPsA) 33.4\%. No patients with seropositive polyarthritis achieved remission status $(p<0.001)$. In remitted patients the mean survival function $( \pm$ SEM) before relapse calculated by life table survival curve was of $20.9( \pm 1.3)$ months overall: $21.7( \pm 0.46)$ in persistent oligoarthritis, $25.0( \pm 6.6)$ in extended oligoarthritis, 26.7 $( \pm 13.2)$ in seronegative polyarthritis and $17.6( \pm 2.44)$ in ERA+JPsA. The log rank test did not show a significant difference between the JIA categories survival curves ( $\mathrm{p}=$ 0.1 ). In our cohort about one-third of cases obtained a remission episode in 4 decades of observation. Finally, if a remission was achieved, the mean duration before a relapse was about 20 months. 